\title{
Fish Stocks Around the Gezhouba and Their Response During Fishing Moratorium in the Yangtze River, China
}

\author{
Congfeng Wang*†, Ping Zhao*(**), Defu Liu***, Jianguo Wang****, Xiaohui Qin*****, Lvbo Liu**** \\ and Zhengjian Yang* \\ * Hubei Field Observation and Scientific Research Stations for Water Ecosystem in Three Gorges Reservoir, \\ Three Gorges University, Yichang 443002, P. R. China \\ **College of Civil Engineering, Guizhou University, Guiyang 550025, P. R. China \\ *** College of Resources and Environment, Hubei University of Technology, Wuhan 430068, P. R. China \\ ****The Pearl River Hydraulic Research Institute, Guangzhou 510611, P. R. China \\ ****** Department of Civil and Geomatics Engineering, Lyles College of Engineering, California State University, \\ Fresno 559-278-5634, USA \\ $\dagger$ Corresponding author: Congfeng Wang; wangcf274407@163.com
}

Nat. Env. \& Poll. Tech.

Website: www.neptjournal.com

Received: 03-05-2020

Revised: $13-06-2020$

Accepted: 16-07-2020

Key Words:

Gezhouba Dam

Fish stocks

Fishing moratorium

Hydro-acoustics

\begin{abstract}
To explore the impact of the fishing moratorium on fish stocks, some parameters and environmental factors were monitored downstream of Gezhouba Dam in April, June and August of 2013. Fish density and target length were get using hydro-acoustics (DIDSON). The results indicated that the fish density distributions in April, June and August were significantly different. The fish density decreased with time but kept a level that was close and steady in April and June. The average fish density of April was significantly greater than that in August $(\mathrm{P}<0.05)$. The percentage of fish target length distribution was consistent in time and space. In the study, the hydraulic and environmental factors were not the main reasons for the decrease of fish density and target body length in the spatial and temporal scale. Overfishing was the main cause and the fishing moratorium was substantially effective for keeping the sustainability of the fish resources in the adjacent areas of Gezhouba Dam.
\end{abstract}

\section{INTRODUCTION}

Building dams in a river causes habitat fragmentation by obstructing the migration pathway for fish and interrupting their reproduction (García et al. 2011, Morita \& Yamamoto 2002, Macdougall et al. 2007, Santos et al. 2006). It negatively affects fish community structure and declines the fish stocks (Yi et al. 2010, Draštík et al. 2008, Yang et al. 2012). The Gezhouba Dam and the Three Gorges Dam are the largest two hydraulic structures in the middle reach of the Yangtze River. They exert much pressure on the downstream fish resources. The Gezhouba Dam is located at the end of the Three Gorges and is the only pathway for fish migration. It is dense for the local fish and partly for the migration fish (Yi et al. 2010, Zhou et al. 2014). The local fish species mainly include the four major Chinese carps. The migration fish species include Chinese sturgeon, Coreius heterodon, and Coreius guichenoti. The migration fish mainly inhabits and spawns in the Dajiang area, while the four major Chinese carps inhabit the Sanjiang area. Because the investigation area is the gathering place of different fish species which come from upstream and downstream of the Yangtze River, it is the favourite fishing area for fishers (Liu et al. 1990, Tao et al. 2010). The main fish species in the middle reaches of the Yangtze River reduce because of overfishing and the varying ecological environment (Yi et al. 2010, Liu et al. 2004, Yi et al. 2010). To restore the fish resources and protect fish biodiversity of the Yangtze River, the Ministry of Agriculture of China has promulgated the regulation of closing fishing in spring since 2003 (Duan et al. 2008).

The impact of fishing moratorium or the prohibited fishing areas on rejuvenating fish stocks has been widely investigated (Moustakas et al. 2006, Bavinck et al. 2008, Barnes \& Sidhu 2013). For example, how fishing moratorium affects fishery production using the Cymbula Granatina model has been studied for more than ten years. And the target parameters of the modelling research include body length, wet flesh mass of individual, growth rate and mortality rate (Arendse et al. 2007). Although reasonable and sophisticated modelling results can be obtained, the 
model development is unsatisfied on time-consuming. And the model application was constrained by many real-world conditions and calculation capacity. Some researchers studied how fishery production was affected by closures of fishing areas under four distinct management strategies (Barnes \& Sidhu 2013). This method provided an indirect assessment of the impact of marine fishery management on fishing fishery resources. The fishing closure measures are evaluated by analysing the evolution of fish community structure and catches biodiversity on time sequence (Duan et al. 2008, 2013). The fish catches of direct acquisition on time sequence provide relatively accurate information, but it may damage the limited fish resources. According to these previous studies, fishing closure has been widely used as an effective measure to ensure the reliability of fishery production (Barnes \& Sidhu 2013). Among various technologies for fishing closure investigation, fisheries hydro-acoustic technology, especially the Dual-frequency Identification Sonar (DIDSON), has been extensively applied in fish resources detection (Tao et al. 2012, Petreman et al. 2014, Han et al. 2009, Boswell et al. 2008, Maxwell \& Smith 2007, Maxwell \& Gove 2004). The goal of this study was to evaluate the impact of the fishing moratorium on the fish stocks near the Gezhouba Dam area using water fisheries acoustics technology, which had the advantages of zero damage to fish resources, easy operation and high precision. The acoustic information was collected using DIDSON with an acoustic camera in the near-dam area. Flow velocity and some water quality data including water temperature, $\mathrm{pH}$ and $\mathrm{DO}$ were monitored at the same time.
Fish density and fish body length were used as the target parameters to quantify the fish and were statistically analysed to correlate with flow velocity and the environmental factors. Finally, the conclusion of the relationship between the fishing moratorium and fish resources was reached.

\section{MATERIALS AND METHODS}

\section{Study Area}

According to the regulation enacted by the Ministry of Agriculture of China (Misund 1997), the closed fishing period in the middle and lower reaches of the Yangtze River is from April 1 to June 29. The study time was on 3-5 April, 22-24 June, 4-5 August, and the acoustic data and water quality data (Water temperature, $\mathrm{pH}, \mathrm{DO}$, and Flow velocity) were collected meanwhile. The investigation area covers four kilometres long of the Gezhouba Dam mainstream. Based on the riverbed topography, flow characteristics, and water quality properties, the investigation area was divided into three regions including the Dajiang region (DJ), the confluence region (CF), and the Sanjiang region (SJ). The three regions were further divided into eight sub-regions. Eight sub-regions are as follows 1\# Ship-lock (I), First station (II), Second station (III), Ship-yard (IV), Miao-zui (V), Junction (VI) Third bridge (VII), 2\# and 3\# Ship-lock (VIII). DJ included sub-regions I-V, CF included sub-region VI, and SJ included sub-regions VII-VIII (Fig. 1). The " $Z$ " shaped lines in Fig.1 were the regional monitoring roadmap.
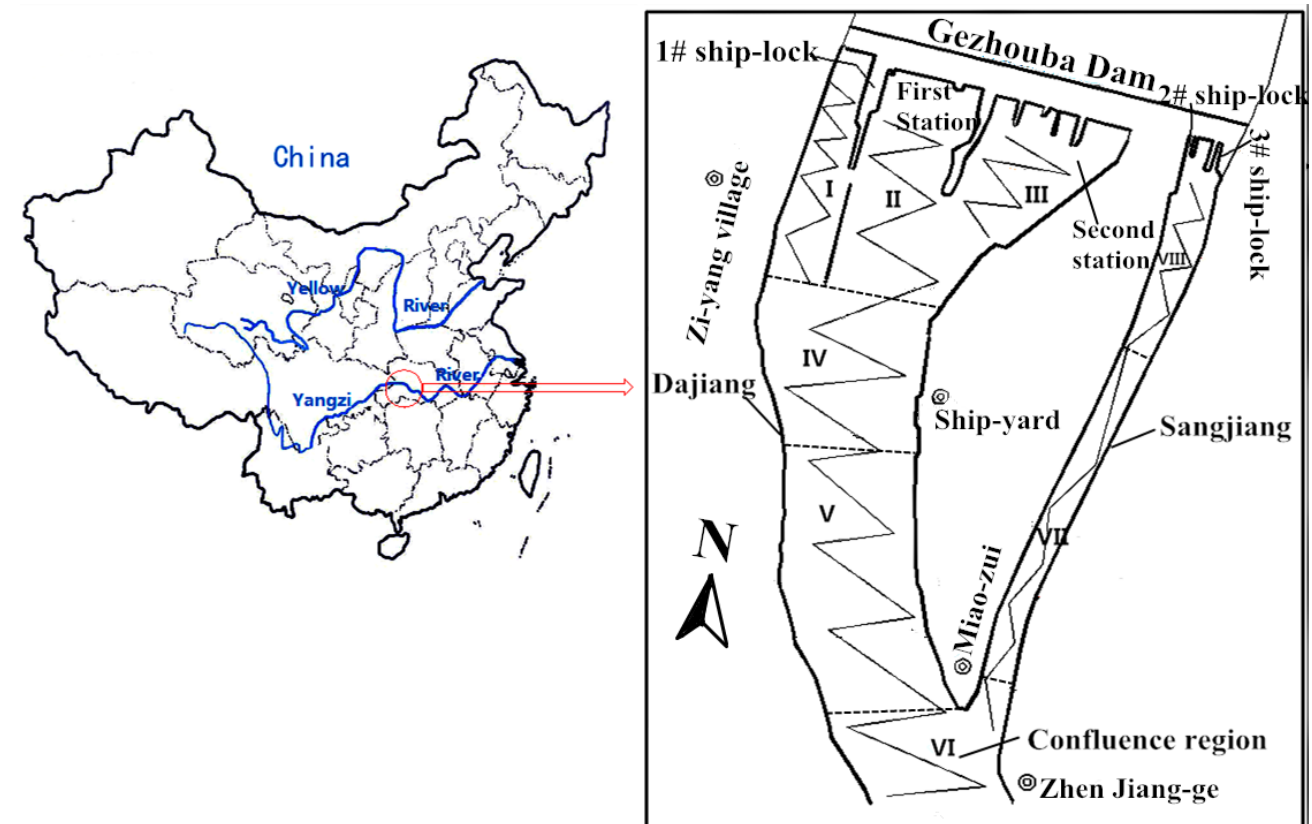

Fig.1: Location of the study area in the Gezhouba Dam. 


\section{Methods}

The fish were real-time identified and monitored using dual-frequency identification sonar (DIDSON) SMC300produced by the Sound Metrics Company of the USA. The monitoring route was positioned using a GPS apparatus (Mobile Mapper 10). The hydro-acoustic data were processed with the auxiliary software DIDSON V5.25 for the fish count. Some water quality parameters including water temperature, $\mathrm{pH}, \mathrm{DO}$ and water depth were obtained using the multi-parameter water quality analyser Hydrolab-DS5 made by Hach Company and the data were exported to Excel processed; flow-velocity using the VectrinoPlus produced by Norway Nortek Company. The DIDSON mounted on the starboard side of the boat was used to monitor the fish distribution downstream of the Gezhouba Dam. Fig. 1 shows the distribution of the monitoring and sampling locations. The mean cruise speed of the sampling boat was maintained as $7 \mathrm{~km} / \mathrm{h}$. The submerged depth of the boat was $0.5 \mathrm{~m}$ and the angle between the axis of the DIDSON and the horizontal direction was maintained $30^{\circ}$. The monitoring route was z-shaped as showed in Fig. 1. The operating frequency of the sonar was adjusted corresponding to the varying bottom elevation of the river during the cruise. The water quality data and flow velocity were monitored at each flexion point on the route.

\section{Data Analysis}

Fish density $(\rho)$ : Fish density $(\rho)$ can be defined as the ratio of the count of fish to the bulk volume when fish is sparsely distributed in spatial as individuals (Misund 1997). The count of fish can be obtained from the DIDSON detecting fish within a pyramid range (Fig. 2) and $\rho$ can be calculated as follows:

$$
\begin{gathered}
\mathrm{b}=2 \mathrm{~h} * \tan 7^{\circ} \\
\mathrm{S}_{\mathrm{b}}=0.5 \mathrm{~h} \mathrm{~b} \\
\mathrm{~V}=\mathrm{S}_{\mathrm{b}} * \mathrm{~L}_{\mathrm{s}} \\
\rho=1000 \mathrm{n} / \mathrm{V}
\end{gathered}
$$

Where $h$ is the length of water body detected by DIDSON $(\mathrm{m}), \mathrm{b}$ is the width of the end section of the pyramid (m), $\mathrm{S}_{\mathrm{b}}$ is the vertically projected area of the pyramid side $\left(\mathrm{m}^{2}\right), \mathrm{L}_{\mathrm{s}}$ is the cruise distance of the ship (m), V is the pyramid bulk volume of the detected water $\left(\mathrm{m}^{3}\right), \rho$ is the fish density in the study (ind. $/ 1000 \mathrm{~m}^{3}$ ), $\mathrm{n}$ is the count of the detected fish in the area.

Fish body length: The Fish Target Strength was defined by referring to the general Sonar Target Strength (TS) formula as follows:

$$
\mathrm{TS}=10 \log \left(\mathrm{I}_{\mathrm{r}} / \mathrm{I}_{\mathrm{i}}\right)
$$

Where $I_{i}$ is the incident acoustic intensity, $I_{r}$ is the acoustic intensity of the reflection at the location $1 \mathrm{~m}$ from the target acoustic centre. TS is the key parameter for both quantitatively evaluating fish resources and fish size inversion. The literature has shown that fish TS depends not only on the body characteristics but also on the wavelength of the acoustic emission (Rakowitz et al. 2008, Knudsen et al. 2004, Godlewska et al. 2012). Richard (1969) believed that since the condition of $1 \leq \mathrm{L} / \lambda \leq 100$, is suitable for most fish in
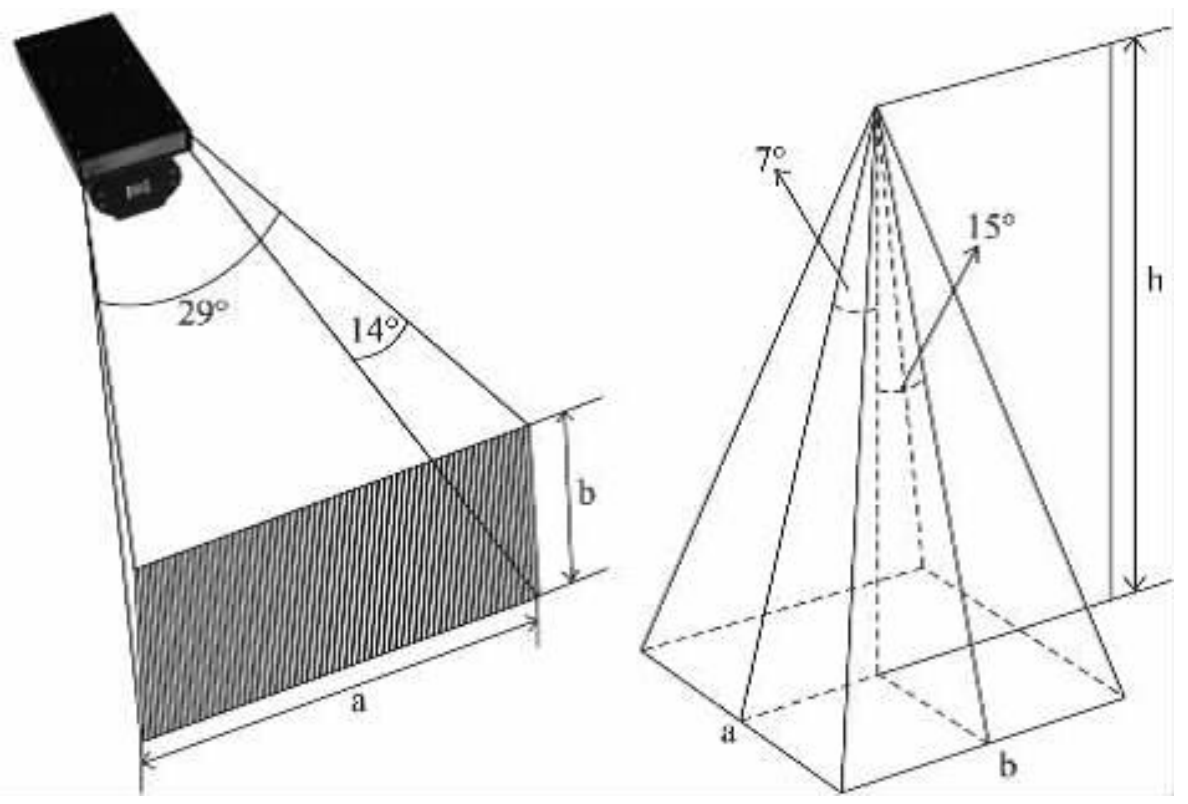

Fig. 2: Sketch of the fish detection range of DIDSON for fish density calculation. 
freshwater, the TS for an individual body can be calculated with the following formula,

$$
\mathrm{TS}=24.1 \log \mathrm{L}-4.1 \log \lambda-33.2
$$

Where $L$ is the target length; lambda $\lambda$ is the acoustic wavelength. Based on the above principle, the information of fish body length and the corresponding distribution can be automatically collected with the DidsonV5.25 software.

The literature of the fish study in the Gezhouba area shows that the body length ranges of the four major Chinese carps are 140 to $1100 \mathrm{~mm}$ during 1994 to 1999,53 to 750 $\mathrm{mm}$ with the acoustic strength of $-58-35 \mathrm{~dB}$ in the reach from Gezhouba Dam to Gulaobei during 2004 to 2006 (Liu et al. 2004, Zhang et al. 2007). The target body length in 2008 was $753 \mathrm{~mm}$ with the maximum acoustic strength of $35.07 \mathrm{~dB}$. In summary, the fish body length remained in the range of $0-1000 \mathrm{~mm}$ except that some general Pro long fish occasionally appear during the Chinese sturgeon spawning period (between October and November) near Gezhouba Dam area. When a high-density fish group was detected with the DIDSON, the group was identified as one single fish body (Liang et al. 2012) with an exceptionally large size, which needs to be screened from the data series. Therefore, to study the relationship between fish density the distribution of the target body length, the fish only with the length between 0 and $100 \mathrm{~cm}$ were counted. The collected data were statistically analysed according to SPSS19.0 with Kolmogorov-Smirnov (K-S) method to investigate fish density distribution and to test the normality of fish density and distribution and the target body length. To distinguish the difference caused by different periods during the closed season, the t-test was conducted for fish density distribution and target body respectively between any two independent samples collected during April, June, and August. The result $(\mathrm{P}<0.05)$ shows the difference is statistically significant (Shen et al. 2007).

Water quality and velocity: Water quality data were collected for each meter below surface water at five different locations in each sub-region. The monitoring data were used to calculate the average velocity and water quality parameters. The $\mathrm{t}$-test result $(\mathrm{p}<0.05)$ for water quality and flow velocity of any two independent samples from the three periods showed the difference is statistically significant. Finally, to identify the decisive factors affecting fish density distribution, some sensitivity analysis was conducted using ANOVA analysis by SPSS19. Several environmental parameters, including water quality, flow velocity, and time, were set as independent variables varied with an interval within a typical range, and fish density was used as a dependent variable (Gao et al. 2008).

\section{RESULTS}

\section{Fish Density $(\rho)$ Distribution}

Table 1 shows fish density in all stages of closure. The fish density of I-VIII were 22.86, 67.74, 34.12, 14.54, 14.25, 2.45, $2.69,7.03$ ind./ $1000 \mathrm{~m}^{3}$ in April, III was the maximum while VI was minimum. The fish density of I-VIII was 15.24, 2.3, $13.34,6.40,6.33,0.3,4.77,10.56$ ind./1000 $\mathrm{m}^{3}$ in August, and the fish density of I was the maximum while VI was minimum. The fish density of DJ was significantly higher than that of the Confluence region and SJ. Especially, the fish density of II-III in April and June was larger than other sub-regions. In II and III, the average fish density in April was 50.93 ind. $/ 1000 \mathrm{~m}^{3}$, and 40.21 ind. $/ 1000 \mathrm{~m}^{3}$ in June. It was steady in April and June while dropped to 7.82 ind./1000 $\mathrm{m}^{3}$ in August. The fish density in IV and V decreased in June and August.

The complexity in underwater topography and flow pattern of the DJ provided the habitat, bait and spawning grounds for various fish with different ecological habits, especially for jet-flow and slow-flow fish. The intrusion of wastewater from upstream Zi-yang village caused an increase in water temperature and sunlight exposure. Then zooplankton and phytoplankton bloomed in sub-region I. The blooms lead to oxygen depletion and negatively impacted the distribution of fish resources. Therefore, fish density in June and August was lower than that in April. Fish mainly gathered to II in August and III in April and June. II and III had wide cross-sections but few shipping vessels, which provided ideal habitat for fish and a preferable fishing area for fishers. The fish density in IV and V decreased in June and August. There may exist a link between the density drop and some external factors such as the pharmaceutical industry, fishing activities, pollution by vessel manufacture. In the confluence of DJ and SJ, the narrow channel and the high flow rate were not suitable for fish to habitat. Therefore, the fish density in the three stages was low (0.3-4.12 ind./

Table 1: Fish density within a survey region (ind./1000 $\mathrm{m}^{3}$ ).

\begin{tabular}{|lllll|}
\hline Region & Sub-region & April & June & August \\
\hline DJ & I & 22.86 & 13.45 & 15.24 \\
& II & 67.74 & 29.36 & 2.3 \\
& III & 34.12 & 51.06 & 13.34 \\
& IV & 14.54 & 14.48 & 6.40 \\
& V & 14.25 & 6.18 & 6.33 \\
CF & VI & 2.45 & 4.12 & 0.3 \\
SJ & VII & 2.69 & 3.32 & 4.77 \\
& VIII & 7.03 & 5.21 & 10.56 \\
\hline
\end{tabular}


$1000 \mathrm{~m}^{3}$ ). The $\mathrm{SJ}$ is an artificial channel. The flow field in this reach was uniform and the mean velocity (less than 0.5 $\mathrm{m} / \mathrm{s}$ ) was significantly lower than that in the DJ area. In SJ, the operations of $2 \#$ and $3 \#$ ship-lock and scouring sluice caused abundant bait and versatile flow patterns, the fish preferred together in VIII neighbouring ship-locks.

\section{Fish Target Length $(L)$ Distribution}

Fig. 3 and Fig. 4 show percentile distribution of target fish body length in April, June and August in the eight sub-regions I-VIII. The $P_{L}$ curves in sub-region VIII (Fig. 3d and $4 c)$ had a high similarity. The channel in region VIII remains naturally growth conditions with less external interference exerted. The high likeness was also observed in regions II, VI and VII from April to June. However in August when the season was over, the overall body length increase in regions II and VI and decrease in VII. The body length of the fish in the channels was highly-screened using a gill net with a certain hole size in the fishing season (Liang et al. 2012). In all stages of the season (April-August), $P_{L}$ values varied with $L$ values within $0-50 \mathrm{~cm}$ significantly and irregularly in regions I, III, IV, and V. This shows that fish growth in these areas was either randomly affected by the municipal and industrial pollution or disturbed by overfishing.
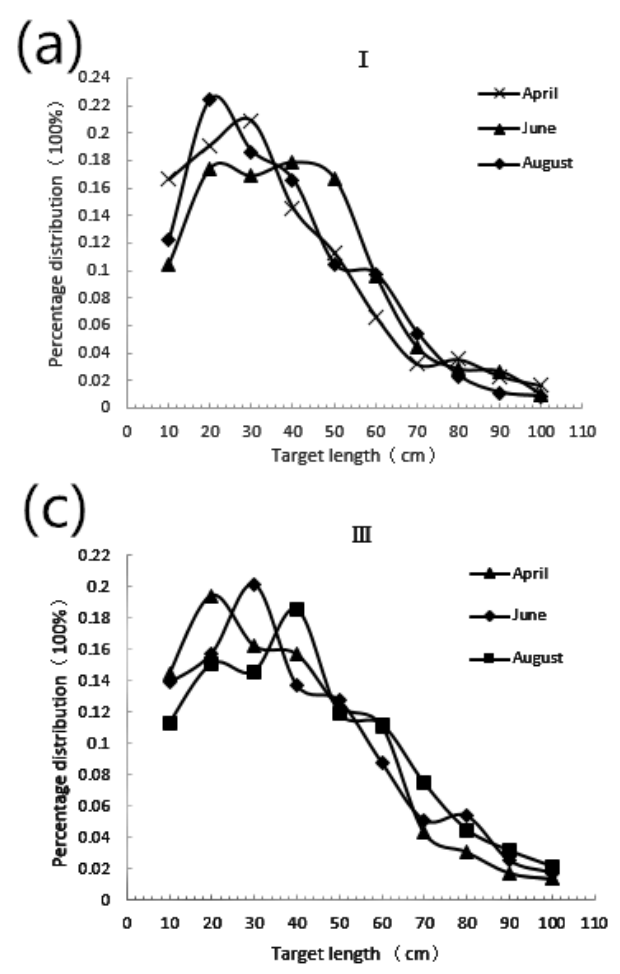

\section{Distribution of Temperature, DO, pH and Flow-Velocity}

The results of the t-test for any two independent samples indicate that there is no significant difference in velocity at different stages of the season $(\mathrm{P}>0.05)$. The spatial distribution of velocity was determined by the underwater topography, operations of the power station and the sluice. The cooperative operations of the Three Gorges reservoir and Gezhouba reservoir resulted in fewer variations of flow rate and flow speed in different seasons. The flow speed in all regions except VI and IV was steady during the three surveying periods. And the change of the original hydrological conditions and the disappearance of scouring and silting under seasonal flooding impact impacted the downstream fish. Water temperature is another important parameter that affects the living, metabolism, reproductive behaviour and population of aquatic organisms, and eventually affect mass circulation, energy redistribution, and function of the aquatic ecosystem. The survey results (Table 2) showed the temperature changed significantly in different stages of the season ( $\mathrm{P}<0.05$ in two independent sample t-test: $)$ and the changing range was $16.15+0.62^{\circ} \mathrm{C} 27.19+0.08^{\circ} \mathrm{C}$. Comparing with temperature, the change of $\mathrm{pH}(8.12 \pm 0.05-9.35 \pm$ $0.1)$ and flow-velocity $(0.93 \pm 0.23 \mathrm{~m} / \mathrm{s}-1.07 \pm 0.2 \mathrm{~m} / \mathrm{s})$ was not obvious.
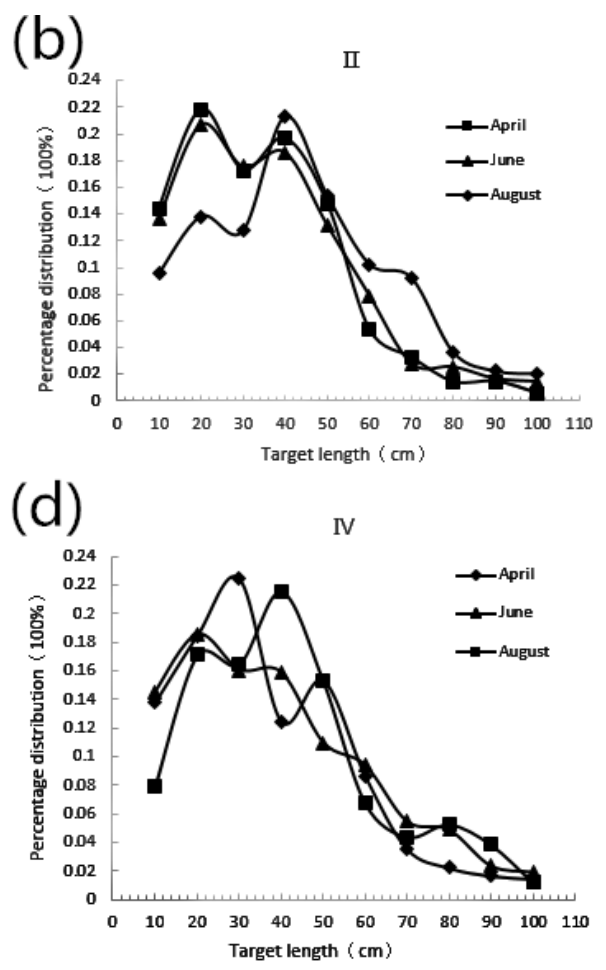

Fig. 3: Percentile target length $\left(P_{L}\right)$ distribution in regions I-IV. 
(a)

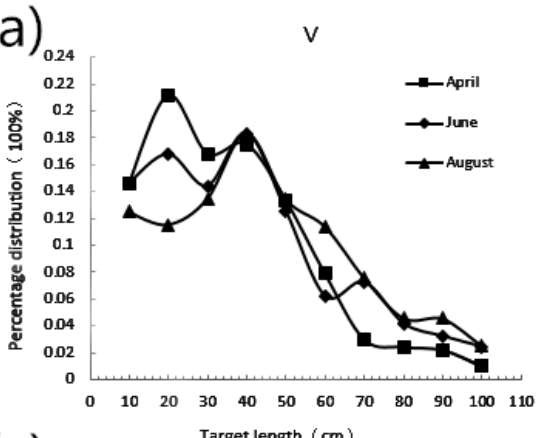

(c)

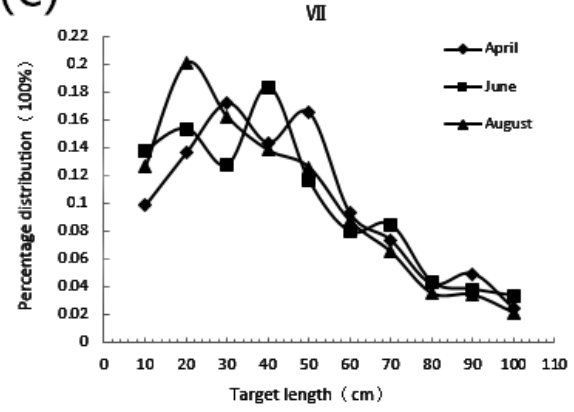

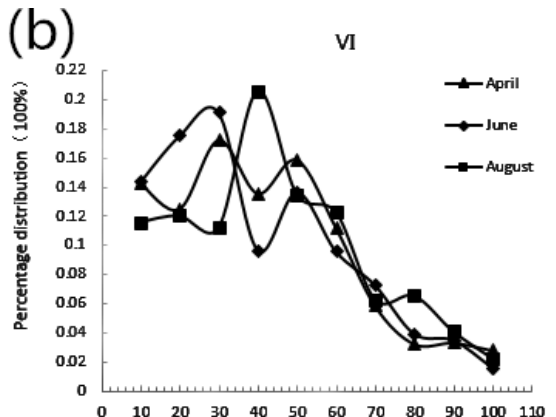

(d)

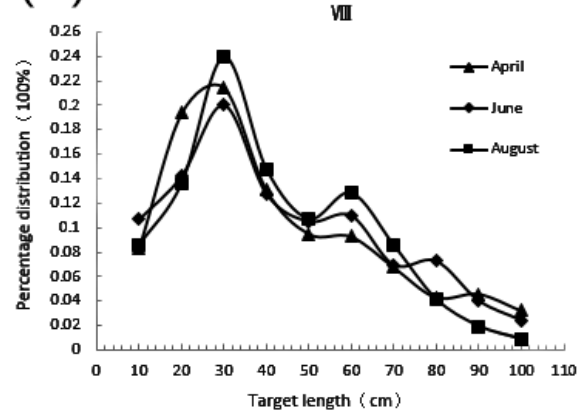

Fig. 4: Percentile target length $\left(P_{L}\right)$ distribution in regions V-VIII.

Relationship between Flow rate, Temperature, DO and pH

The temperature range was divided into three zones, 14.38 $18.34^{\circ} \mathrm{C}, 23.34-24.21^{\circ} \mathrm{C}$ and $26.92-27.56^{\circ} \mathrm{C}$, to study the impact of the temperature. Previous studies show that the lowest spawning temperature for Coreius heterodon and Coreius guichenoti is $17^{\circ} \mathrm{C}$ and the temperature during the peak spawning period is $19-22^{\circ} \mathrm{C}$ (Liu et al. 1990). The lowest breeding temperature for the four major Chinese carps is $18^{\circ} \mathrm{C}$ and the temperature during the peak spawning is $21-24^{\circ} \mathrm{C}$. All these species concentrated to spawn only in the fishing moratorium. The Kolmogorov-Smirnov analyses showed that the fish density was not normally distributed within the range of $23.34-24.21^{\circ} \mathrm{C}$. However, it appeared normal distribution with a Sig of 0.254 (which was greater than 0.05 ) after conducting logarithmic conversion. The $\mathrm{F}$ of 2.478 and $P$ of 0.024 (which was less than 0.05 ) in the Anova results showed significant differences in the fish distribution density at different temperature levels.

To analyze the impact of flow-velocity on fish density distribution, the monitoring data of the flow velocity was divided into three ranges, $0-0.7 \mathrm{~m} / \mathrm{s}, 0.7-1.2 \mathrm{~m} / \mathrm{s}$ and $1.2-2.1 \mathrm{~m} / \mathrm{s}$. The Kolmogorov-Smirnov test showed that the fish density was normally distributed in three ranges. In the ANOVA

Table 2: Temperature, DO, pH of regions I-VIII in April, June and August.

\begin{tabular}{|c|c|c|c|c|c|c|c|c|c|}
\hline \multirow[t]{2}{*}{ zone } & \multicolumn{3}{|c|}{ Temperature $\left({ }^{\circ} \mathrm{C}\right)$} & \multicolumn{3}{|l|}{$\mathrm{pH}$} & \multicolumn{3}{|c|}{$\mathrm{DO}(\mathrm{mg} / \mathrm{L})$} \\
\hline & April & June & August & April & June & August & April & June & August \\
\hline I & 18.34 & 23.56 & 27.13 & 8.09 & 8.63 & 9.12 & 9.78 & 7.86 & 7.45 \\
\hline II & 17.99 & 23.35 & 26.96 & 8.21 & 8.40 & 9.15 & 9.48 & 7.49 & 7.11 \\
\hline III & 18.32 & 23.34 & 26.92 & 7.91 & 8.50 & 9.32 & 7.91 & 7.46 & 7.10 \\
\hline IV & 14.38 & 23.37 & 27.01 & 8.13 & 8.53 & 8.96 & 8.31 & 7.62 & 7.13 \\
\hline $\mathrm{V}$ & 14.41 & 24.09 & 27.36 & 7.87 & 8.48 & 9.58 & 8.43 & 7.68 & 6.74 \\
\hline VI & 15.09 & 24.21 & 27.56 & 8.15 & 8.09 & 9.82 & 8.18 & 8.89 & 6.45 \\
\hline VII & 15.32 & 24.15 & 27.37 & 8.27 & 8.54 & 9.25 & 8.55 & 8.08 & 6.48 \\
\hline VIII & 15.37 & 23.98 & 27.21 & 8.31 & 8.68 & 9.56 & 8.09 & 7.50 & 6.56 \\
\hline
\end{tabular}


results, the $\mathrm{F}$ was 28.56 and $\mathrm{P}$ was $0.007(<0.05)$ indicating that the fish distribution density at different flow-velocity levels was different. It showed that in the near-dam area of downstream Gezhouba, the fish had selectivity to the velocity of three ranges. The flow velocity could affect fish density distribution.

The average values of $\mathrm{DO}$ and $\mathrm{pH}$ showed no significant differences ( $p>0.05)$, and the survey would not be discussed in this paper (Table 2).

\section{DISCUSSION}

\section{Influence of Environmental Factors on the Fish Distribution in Spatial and Temporal}

Many studies have investigated the influence of ecological factors including water temperature, $\mathrm{DO}$, velocity, $\mathrm{pH}$, the availability of food on the spatial and temporal distribution of fish (Yi et al. 2010, Yuan et al. 2012, Liu et al. 2009, Xiong et al. 2014). In particular, the water temperature has a close relationship with survival, metabolism, reproductive behaviour and the population distribution of aquatic organisms (Wang et al. 2008). The monitoring data showed the fish density in the area adjacent to the Gezhouba Dam was spatially and temporally affected by water temperature and flow velocity. The average water temperature significantly increased from $16.15^{\circ} \mathrm{C}$ in April to $23.75^{\circ} \mathrm{C}$ in June and to $27.19^{\circ} \mathrm{C}$ in August. The water temperature in April was too low for the majority of the local fish to spawn. Some studies have reported that Coreius heterodon, Coreius guichenoti and Pelteobagrus fulvidraco mainly eat fish eggs as the primary food and their percentage often change (Luo et al. 20013). The spawning water temperature of Pelteobagrus fulvidraco is from 24 to $28^{\circ} \mathrm{C}$. The broodstock largely consumes food when the water temperature is higher than $15^{\circ} \mathrm{C}$ and its peak breeding season is from May to July. Cyprinus carpio and Siniperca chuatsi mainly distribute in SJ. The most suitable temperature for Siniperca chuatsi to actively prey, swim, is from 23 to $25^{\circ} \mathrm{C}$. The four major Chinese carps are the primary fishes near the Gezhouba Dam in upstream of the Yangtze River to support the local economy. The rich fish stocks in June and August was probably associated with a large quantity of breeding occurring meanwhile. The earliest and the latest beginning date for the four major Chinese carps to spawn is April 28 and May 10, and the lasts tending date is June 15 and July 5 . The optimum temperature range for growth and reproduction is from $22^{\circ} \mathrm{C}$ to $28^{\circ} \mathrm{C}$ (Guo et al. 2011). Therefore, if only considering the effect of temperature on fish density, the fish density in the near dam area should increase with the increase of temperature to a certain extent However, the monitoring data did not reflect the analysis. On the contrary, the fish density showed a decreasing trend from April to June and August. Therefore, the temperature was not the key factor for fish density change in this research scale.

Fish density distribution is closely related to hydrologic conditions including water depth, flow velocity, flow rate and flow direction (Guo et al. 2011, Kynard 1995). Among these factors, fish determines its swimming route, even migratory route, based on its sense to the flow velocity (Yuan et al. 2011). The results in this study have confirmed the influence of the flow speed on the fish density distribution in the near-dam region, which is consistent with Zhang Huijie (2007). While the mainstream in II and III kept average flow-velocity greater than $1.4 \mathrm{~m} / \mathrm{s}$, it provided a steady habitat for fish and led to high fish densities. The majority of the species in II and III are slow-current loving type fish, such as Pelteobagrus fulvidraco and Coreius heterodon (Liu et al. 2012). All three monitoring results indicated the greater fish density occurs in the area close to the dam (Table 1), and the flow velocity in this region was distributed in the range of fish's favourite and the extreme velocities. Therefore, the flow field was suitable for most fish to live in. Fish habitat is also affected by the underwater topography (Ban \& Li 2007), so the diversion dike may diversify the flow patterns in the river reach to maintain biological diversity.

\section{Influence of the Fishing Moratorium on Downstream Fish Stocks of the Gezhouba}

The body length of catches or acoustic body length is directly or indirectly used to analyze the community structure and growth trends of fish, to evaluate the temporal change of fish stocks and the effect of the fishing moratorium (Liu et al. 2004, Duan et al. 2008, Zhang et al. 2006, Li et al. 2014). In this study, comparing with the observation of August when the fishing moratorium was over, the echo signals of target length within 10-40 cm were stronger in most areas in the closed season both in April and June. Although the echo signals of some body lengths were increased in a few regions, there was no significant difference $(\mathrm{P}>0.05)$ for the overall target length. The fish density substantially varied with different monitoring areas and it decreased significantly from April to August. The water quality analysis showed little impact of the DO, $\mathrm{pH}$ and water temperature on the fish density. Although the fish density was much sensitive to the flow velocity in the three monitoring, there was no significant difference between the periods of the fishing moratorium and after the fishing moratorium. So the flow-velocity was not a key factor for fish stocks in the research scales.

The fish stocks kept a stable level during the fishing moratorium. Once the fishing moratorium was over on June 31 , many fishing activities were conducted in the near-dam area. Monitoring results of August showed the overall fish 
density dropped and it plummeted in some areas where fish densely distributed in April and June. This was mainly caused by fishing activities with high frequency in the near-dam during the fishing season. Therefore, the fishing moratorium played a key role in maintaining the sustainability of fish and overfishing was one major factor related to the decline of fish stocks during the investigation period. This conclusion was consistent with Arendse et al. (2007).

\section{CONCLUSIONS}

As one of the most important measures of management, the fishing moratorium plays an important role to protect the fish resources in the Yangtze River. The results of this study demonstrated that there existed a significant difference in fish density distributions in April, June and August. The distribution in DJ was much higher than that in SJ. The fish density generally decreased with time but maintained a close and steady level in April and June. The average density of April was significantly greater than that in August $(\mathrm{P}<0.05)$. The percentage of fish body length distribution was fairly uniform in time and space. In this study, the change of temperature and flow velocity were not the main reasons for the decrease in fish density and target body length. The fishing moratorium had an obvious effect on maintaining the stability of fish resources near Gezhouba. Overfishing was one of the important reasons for the decline of fish resources.

\section{ACKNOWLEDGEMENTS}

This study was financially supported by the National Natural Science Foundation of China (Grant No. 52079074, 91647207, 51879099, 51709096 and 51779128), Non-profit Industry Program for special scientific of Ministry of Water Resources of China (No. 201201030), and Young talents project of Guizhou Provincial Department of Education KY(2017)120.

\section{REFERENCES}

Arendse, C.J., Govender, A. and Branch, G.M. 2007. Are closed fishing seasons an effective means of increasing reproductive output? : A per-recruit simulation using the limpet Cymbula granatina as a case history. Fisheries Research, 85: 93-100.

Ban, X. and Li, D.M. 2007. Ecological hydrological influence of large water conservancy projects on Acipenser Sinensis in Yangtze River. Engineering Journal of Wuhan University, 40: 10-13.

Barnes, B. and Sidhu, H. 2013. The impact of marine closed areas on fishing yield under a variety of management strategies and stock depletion levels. Ecological Modelling, 269: 113-125.

Bavinck, M., De Klerk, L., Van Dijk, D., Rothuizen, J.V., Blok, A.N., Bokhorst, J.R., Van Haastrecht, E.K., van de Loo, T., Quaedvlieg, J. and Scholtens, J. 2008. Time-zoning for the safe-guarding of capture fisheries: A closed season in Tamil Nadu, India. Marine Policy, 32: 369-378.
Boswell, K.M., Wilson, M.P. and Cowan Jr, J.H. 2008. A semiautomated approach to estimating fish size, abundance, and behavior from dualfrequency identification sonar (DIDSON) data. North American Journal of Fisheries Management, 28: 799-807.

Draštík, V., Kubečka, J., Tušer, M., Čech, M., Frouzová, J., Jarolím, O. and Prchalová, M. 2008. The effect of hydropower on fish stocks: Comparison between cascade and non-cascade reservoirs. Hydrobiologia, 609: 25-36.

Duan, X.B., Liu, S.P., Xiong, F., Chen, D.Q., Yang, R.H., Chi, C.G. and $\mathrm{Mu}$, T.R. 2008. Analysis of fishing structure and biodiversity in the upper mainstream of the Yangtze River before and after three years' spring fishing off. Resources and Environment in the Yangtze Basin, 17: 878-885.

Gao, Z. J., Shi, S. L. and Li, Y. 2008. Application of SPSS in ANOVA of biological statistics. Progress in Modern Biomedicine, 2116-2120.

García, A., Jorde, K., Habit, E., Caamaño, D. and Parra, O. 2011. Downstream environmental effects of dam operations: changes in habitat quality for native fish species. River Research and Applications, 27: 312-327.

Godlewska, M., Frouzova, J., Kubecka, J., Wiśniewolski, W. and Szlakowski, J. 2012. Comparison of hydroacoustic estimates with fish census in shallow Malta Reservoir - which TS/L regression to use in horizontal beam applications? Fisheries Research, 123-124, 90-97.

Guo, W. X., Wang, H. X., Xu, J. X. and Xia, Z. Q. 2011. Effects of Three Gorges reservoir on the downstream eco-hydrological regimes during the spawning of important fishes. Journal of Hydroelectric Engineering, 30: 22-26.

Han, J., Honda, N., Asada, A. and Shibata, K. 2009. Automated acoustic method for counting and sizing farmed fish during transfer using DIDSON. Fisheries Science, 75: 1359-1367.

Knudsen, F.R., Fosseidengen, J.E., Oppedal, F., Karlsen, $\varnothing$ and Ona, E. 2004. Hydroacoustic monitoring of fish in sea cages: target strength (TS) measurements on Atlantic salmon (Salmo salar). Fisheries Research, 69: 205-209.

Kynard, B., Wei, Q.W. and Ke, F.N. 1995. Use of ultrasonic telemetry to locate the spawning area of Chinese sturgeons. Chinese Science Bulletin, 40: 668-671.

Liu, L.H., Wang, G.X. and Wang, Z.L. 1990. Reproduction ecology of Coreius heterodon and Coreius guichenoti in the mainstream of the Yangtze River after the construction of Gezhouba Dam. Acta Hydrobiologica Sinica, 14: 205-215.

Li, Y.F., Li, X.H., Yang, J.P., Lek, S., Shuai, F.M. and Li, J. 2014. Effect of Pearl River closed fishing on Megalobrama hoffmanni recruitment stock. Journal of fisheries of China, 38: 502-508.

Liang, Z.L., Yan, W., Sun, P., Huang, L.Y. and Tang, Y.L. 2012. A study on the impact of Gill Net on the phenotypic traits of fish population. Oceanologia Et Limnologia Sinica, 43: 329-334.

Liu, C.C., Gao, X., Lin, P.C., Yang, S.R., Liu, H.Z. and Cao, W.X. 2012. Fish community structure in Gezhouba reservoir. Resources and Environment in the Yangtze Basin, 21: 843-849.

Liu, S.P., Chen, D.Q., Duan, X.B., Qiu, S.L. and Huang, M.J. 2004. Monitoring of the four famous Chinese carps resources in the middle upper reaches of the Yangze River. Resources and Environment in the Yangtze Basin, 13: 183-186.

Liu, W., ZhuGe, Y.S., Ou, Y.L., Yu, W. and Liu, D.F. 2009. Experimental study of the effect of hydrodynamic conditions on fish growth. Advances In Water Science, 20: 812-817.

Luo, J., Jiang, W., Chen, Q.W., Liu, D.F., Tang, X.L., Tu, Z.Y. and Shi, X.T. 2013. Estimation on abundance of egg-predatory fishes in the spawning ground of Chinese sturgeon below the Gezhouba Dam. Freshwater Fisheries, 43: 27-30.

MacDougall, T.M., Wilson, C.C., Richardson, L.M., Lavender, M. and Ryan, P.A. 2007. Walleye in the Grand River, Ontario: an overview of 
rehabilitation efforts, their effectiveness, and implications for eastern Lake Erie fisheries. Journal of Great Lakes Research, 33: 103-117.

Maxwell, S.L. and Gove, N.E. 2004. The Feasibility of estimating migrating salmon passage rates in turbid rivers using a dual frequency identification sonar (DIDSON). Alaska Department of Fish and Game Regional Information Report.

Maxwell, S.L. and Smith, A.V. 2007. Generating river bottom profiles with a dual-frequency identification sonar (DIDSON). North American Journal of Fisheries Management, 27: 1294-1309.

Misund, O.A. 1997. Underwater acoustics in marine fisheries and fisheries research. Reviews in Fish Biology and Fisheries, 7: 1-34.

Morita, K. and Yamamoto, S. 2002. Effects of habitat fragmentation by damming on the persistence of stream-dwelling charr populations. Conservation Biology, 16: 1318-1323.

Moustakas, A., Silvert, W. and Dimitromanolakis, A. 2006. A spatially explicit learning model of migratory fish and fishers for evaluating closed areas. Ecological Modelling, 192: 245-258.

Petreman, I.C., Jones, N.E. and Milne S.W. 2014. Observer bias and subsampling efficiencies for estimating the number of migrating fish in rivers using Dual-frequency Identification Sonar (DIDSON). Fisheries Research, 155: 160-167.

Rakowitz, G., Herold, W., Fesl, C., Keckeis, H., Kubečka, J. and Balk, H. 2008. Two methods to improve the accuracy of target-strength estimates for horizontal beaming. Fisheries Research, 93: 324-331.

Santos, J.M., Ferreira, M.T., Pinheiro, A.N. and Bochechas, J.H. 2006. Effects of small hydropower plants on fish assemblages in mediumsized streams in central and northern Portugal. Aquatic Conservation. Marine and Freshwater Ecosystems, 16: 373-388.

Shen, X.P., Ding, J.S., Li, J.S., Liu, X.N., Li, J.H. and Mi, A.J. 2007. 2-Independent-Samples t-test undertaking by the means of mean and standing deviation in SPSS. Modern Preventive Medicine, 4066-4067.

Tao, J., Gong, Y., Tan, X., Yang, Z. and Chang, J. 2012. Spatiotemporal patterns of the fish assemblages downstream of the Gezhouba Dam on the Yangtze River. Science China Life Sciences, 55: 626-636.

Wang, W., Li, W.C., Ma, X.Z., He, L. and Ye, F.F. 2008. Effects of water temperature and light intensity on the behaviors of Pelteobagrus vachelli fingerlings. Chinese Journal of Ecology, 27: 791-796.

Xiong, F., Wang, C.F., Liu, D.F., Wang, L.L., Qin, X.H. and Shi, X.T. 2014. Fish assemblages under different running status of the 1\# ship-lock of the Gezhou Dam. Journal of Hydroecology, 35: 8-14.

Yang, S., Gao, X., Li, M., Ma, B. and Liu, H. 2012. Interannual variations of the fish assemblage in the transitional zone of the Three Gorges Reservoir: persistence and stability. Environmental Biology of Fishes, 93: 295-304.

Yi, Y., Wang, Z. and Yang, Z. 2010. Impact of the Gezhouba and Three Gorges Dams on habitat suitability of carps in the Yangtze River. Journal of hydrology, 387: 283-291.

Yi, Y., Yang, Z. and Zhang, S. 2010. Ecological influence of dam construction and river-lake connectivity on migration fish habitat in the Yangtze River basin, China. Procedia Environmental Sciences, 2: 1942-1954.

Yuan, X., Li, L.P., Tu, Z.Y., Shi, X.T., Liu, G.Y., Liu, D.F. and Huang, Y.P. 2012. A review of fish physiological and ecological behavior responding to river ecological factors. Resources and Environment in the Yangtze Basin, 21: 24-29.

Yuan, X., Tu, Z.Y., Han, J.C., Shi, X.T., Liu, G.Y. and Huang, Y.P. 2011. Effects of flow rate on swimming behavior and energy consumption of Carassius auratus. Journal of Hydroecology, 32: 103-109.

Zhang, H.J., Yang, D.G., Wei, Q.W., Du, H., Zhang, H. and Chen, X.H. 2007. Hydro-acoustic survey on fishes in the reach from Gezhouba Dam to GuLaoBei of the Yangze River. Resources and Environment in the Yangtze Basin, 16: 86-91.

Zhang, M.Y., Liu, K., Xu, D.P. and Shi, W.G. 2006. Primary study on effect of Spring-Fishing-Ban season on fishery community structure and biodiversity in ChangShu section of the Yangze River. Resources and Environment in the Yangtze Basin, 15: 442-446.

Zhou, J., Zhao, Y., Song, L., Bi, S. and Zhang, H. 2014. Assessing the effect of the Three Gorges reservoir impoundment on spawning habitat suitability of Chinese sturgeon ( $<\mathrm{i}>$ Acipenser sinensis) in Yangtze River, China. Ecological Informatics, 20: 33-46. 